\title{
Türk İmalat Sanayinde Performans, İnovasyon ve Rekabet Arasındaki İlişki*
}

\author{
Aykut KARAKAYA ${ }^{1}$ \\ Seymur AĞAZADE 2 \\ Selçuk PERÇİN
}

ÖZ: Performans ve inovasyon ilişkisi literatürde en yaygın biçimde neoklasik iktisat teorisi ve Shumpeteryen görüşte ortaya konulur. Neoklasik teori inovasyonun rekabetçi piyasalarda, Shumpeteryen görüş ise daha çok aksak rekabet piyasalarında ortaya çıkacağını öngörür. Bu çalışmada Türk Imalat Sanayii endüstri kollarının 2008-2013 dönemine ait verileri kullanılarak performans ile innovasyon ve rekabet düzeyi arasındaki ilişki araştırılmıştır. Performans değişkenleri net kar marjl, aktif karlılık oranı ve öz sermaye karlılı oranlarıdır. Inovasyon değişkeni ar-ge yoğunluğudur. Endüstri rekabeti Herfindahl-Hirschman Endeksi ile ölçülmüştür. Tahmin sonucunda aynı dönem ar-ge yoğunluğunun performansı pozitif, bir dönem gecikmesinin ise negatif yönde etkilediği bulunmuştur. Rekabetteki yoğunlaşmanın performansı artırdiğı tespit edilmiştir. Aynı döneme ait ar-ge'nin pozitif etkiye sahip olması inovasyonun rekabet üstünlüğü sağlayıcı özelliğe sahip olduğunu desteklemektedir. Ar-ge'nin gecikmeli etkisinin negatif olması ise fikri mülkiyet haklarının korunmasına ilişkin sorunlara işaret eder. Bu, inovasyon faaliyetlerinin yaklaşık bir dönem sonra taklit edildiği anlamına gelebilir. Rekabetteki yoğunlaşmanın pozitif etkisi ise Schumpeteryen görüs öngörüsünü destekleyici niteliktedir.

Anahtar Kelimeler: İmalat Sanayi, İnovasyon, Rekabet, Panel Veri Analizi JEL Sinıflandırılması: L60, O30, M21, C33

\section{The Relationship between Performance, Innovation and Competition in Turkish Manufacturing Industry}

\begin{abstract}
The relationship between performance and innovation is covered most extensively in neoclassical economic theory and Schumpeterian approach. The neoclassical theory predicts that innovation emerges in competitive markets while Schumpeterian approach predicts it will emerge in imperfect competitive markets. Using data for the period 2008-2013, this study investigates the relationship between innovation and competition level in the Turkish Manufacturing Industry. Performance variables of the study are net profit margin, return on assets and return on equity. $R \& D$ intensity is innovation indicator. Industrial competition level is measured by HerfindahlHirschman Index. The results of Two-Step System Generalized Method of Moments analysis show that $R \& D$ intensity affects positively performance variables in contrast one lag of $R \& D$ effects negatively. Furthermore, competition intensity also improves performance. Positive coefficient of $R \& D$ variable supports the view of innovation has the characteristics of providing competitive advantage. The negative coefficient of $R \& D$ lag indicates the problems related to the protection of intellectual property right. This finding can be interpreted that innovation operations are imitated approximately after a period. The positive effect of competition intensity supports the prediction of Schumpeterian approach.
\end{abstract}

Key Words: Manufacturing Industry, Innovation, Competition, Panel Data Jel Classifacations: L60, O30, M21, C33

Geliş Tarihi / Received: 19/02/2018

Kabul Tarihi / Accepted: 28/03/2018

\footnotetext{
${ }^{*} \mathrm{Bu}$ çalışma 6. Uluslararası Avrasya Ekonomileri Konferansında sunulan "Türk İmalat Sanayinde Performans, İnovasyon ve Rekabet Arasındaki İlişki” isimli bildiriden genişletilerek hazırlanmıştır.

${ }^{1}$ Dr., Öğr. Ü. RTEÜ, İIBF, İşletme Bölümü, aykut.karakaya @ erdogan.edu.tr, orcid.org/0000-0001-6491-132X

${ }^{2}$ Doç. Dr., RTEÜ, İ̈BF, İktisat Bölümü, seymur.agazade@erdogan.edu.tr, orcid.org/0000-0001-5484-5189

${ }^{3}$ Prof. Dr., KTÜ, İIBBF, İşletme Bölümü, spercin@ktu.edu.tr, orcid.org/0000-0002-5840-7204
} 


\section{Giriș}

Firmalar küreselleşmeyle birlikte artan rekabetin olduğu ulusal ve uluslararası piyasalarda, faaliyetlerini kesintisiz ve performanslarını iyileştirerek sürdürmeleri için daha yoğun şekilde inovasyon yapmaktadır. Literatürde inovasyonun performansa etkisini açıklamaya çalışan araştırmalarda son yirmi yılda önemli artış olmuştur. Bu araştırmalar amaçları açısından üç grupta sınıflanabilir. İlkinde, inovasyonun içeriği ve firma performansı arasındaki bağlar karşılaştırılmıştır. İkincisinde, inovasyon türleri ile performans arasındaki bağlar incelenmiştir. İnovasyon ve performans arasındaki ilişki araştırmaların bazısında pozitif, bazısında negatif ve bazısında da anlamsız bulunmuştur (Heunks, 1998; Freel, 2000; Cainelli vd., 2006; Avlonitis ve Salavou, 2007; Rochina-Barrachina vd., 2010). Son grupta, inovasyon ve performans arasındaki ilişkide finansmanın büyüklügü, finansman riski, talep gibi ekonomik koşullar dikkatte alınmıştır. Bu çalışmalarda ekonomik koşulların inovasyon ve performansı etkilediği ortaya konmuştur. İnovasyon performansı etkileyen önemli bir faktör olması ile birlikte performansı birçok başka değişkenin de etkilemektedir. Bunlar arasında rekabet ve teknoloji yoğunluğu ön plana çıkmaktadır (Bessen ve Maskin, 2009; Kim ve Lee 2009; Oh vd., 2015).

Piyasa rekabeti ile firma performansı arasındaki ilişkiye yönelik literatürde farklı görüşler mevcuttur. Söz konusu görüşlerde ilişsinin yönü ile ilgili farklılıklar olmasına rağmen, uzlaşılan husus rekabetin performans üzerindeki belirleyici rolünün olduğudur. Rekabet firmaların stratejik kararlarında göz önünde bulundurdukları kuşkusuz en önemli piyasa bilgileri arasındadır. Performans, inovasyon ve rekabet arasındaki ilişki literatürde yaygın biçimde Neoklasik iktisat teorisi ve Schumpeteryen görüşle açıklanmaktadır. Neoklasik teori inovasyonun rekabetçi piyasalarda, Schumpeteryen görüş ise daha çok aksak rekabet piyasalarında ortaya çıkacağını öngörür.

Firmalar açısından endüstrilerdeki rekabetin yanında teknolojide önemlidir. Ölçek ekonomisi oluşturmasından ötürü teknoloji üretim maliyetlerini düşürmektedir (Oh vd., 2015). Teknoloji, rekabet gibi maliyetleri azaltıp verimliliği artırdığından, firma performansında belirleyici ekonomik sonuçlar doğurmaktadır. Dolayısıyla inovasyon, rekabet ve teknoloji firma performansında önemli ve etkisi uzun süre devam eden stratejik faktörlerdir.

Türk İmalat Sanayiinde inovasyon, rekabet ve performans arasındaki ilişki üzerine yapılmış çalışmalar sınırlı sayıdadır. Hatta NACE Rev.2 endüstri sınıflamasına göre, yapılmış çalışmalara rastlanamamıştır. Bu çalışmada Türk İmalat Sanayiinde inovasyon, rekabet ve performansın ne düzeyde olduğuna ilaveten rekabet yoğunluğu, inovasyon ve teknolojik yoğunluğun performansa etkisinin nasıl olduğu soruları cevaplanmaya çalışılmıştır. Söz konusu soruların cevaplanmasında, firmaların bilanço ve gelir tablolarının ilgili endüstri kolları itibariyle toplulaştırıldığı endüstri bilanço ve gelir tablolarından elde edilen finansal bilgilerden yararlanılmıştır. $\mathrm{Bu}$ doğrultuda endüstri kolları düzeyinde 
2008-20013 yılları bilanço ve gelir tablolarından elde edilen veriler panel veri analiz yöntemlerinden dinamik panel analizi tahmincilerinden içselliği dikkate alan İki Aşamalı Sistem Genelleştirilmiş Momentler Yöntemi aracılığıyla analiz edilmiştir.

Çalışma altı bölümden oluşmaktadır. Birinci giriş bölümünü takiben, ikinci bölümde performans, inovasyon ve rekabet arasındaki ilişki teorik olarak ele alınmıştır. Üçüncü bölümde, çalışmanın veri seti ve değişkenleri hakkında bilgiler verilmiştir. Dördüncü bölümde çalışmanın analiz yöntemleri tanıtılmış ve performans modeli sunulmuştur. Beşinci bölümde araştırma sorularının cevaplandığı araştırma bulguları yer almıştır. Son olarak altıncı bölünde sonuç ve öneriler sunulmuştur.

\section{Firma Performansı, İnovasyon ve Rekabet Arasındaki İlişki}

Firmaların faaliyet gösterdikleri piyasalarda mevcut rekabet yoğunluğunun firma performansına etkisi konusunda farklı görüşler vardır. Neoklasik iktisat teorisi piyasaların daha etkin şekilde çalışması için rekabetin önemli olduğunu varsayar. Etkin piyasalarda faaliyet gösteren firmaların varlıklarını sürdürebilmelerini rekabet edebilmelerine bağlar, rekabetin firmalar için maliyetlerini düşürme ve üretimlerini geliştirme yönünde güçlü teşvikler sağlayacağını belirtir. Böylece Neoklasik iktisat teorisindeki görüş, rekabetin yenilik için yatırım yapma yönünde firmalara teşvik sağladığı yönündedir. Yenilik veya yeni ürünlerin geliştirilmesinde, ürün farklılaştırılmasında firmaların amacı kendilerini rekabet yoğunluğuna karşı korumak veya piyasa gücü elde etmektir. Bu görüşe göre rekabetçi piyasalarda firmalar sahip oldukları kaynakları etkin şekilde kullanma yönünde daha güçlü güdülere sahip olduklarından firma performanslarının da yüksek olması beklenir. Monopolistik piyasa ya da düşük rekabet düzeyi ise firmalara tekniklerini geliştirme yönünde güçlü bir güdü sağlamadığından firma performanslarının da nispeten düşük olması beklenir.

Arrow'un (1962) argümanları da rekabet yoğunluğunun olduğu piyasalarda maliyetleri azaltmaya yönelik daha güçlü teşvikler olduğunu desteklemektedir. Şöyle ki Arrow (1962), buluşların uygun telif hakkı ödenerek ticarileştirilmesi ve fikri mülkiyet haklarının korunması varsayımıyla rekabetçi piyasaların monopolistik özellikler taşıyan piyasalara oranla maliyetleri düşürmeye yönelik yenilik yapma yönünde daha güçlü bir güdü sağladığını ileri sürer. Buna göre düşük rekabetin olduğu piyasalarda maliyetli yenilikleri yapmak veya yeni ürünler geliştirmek için daha az teşvik vardır. Buluş öncesi monopolistik güç daha ileri buluşlar için güçlü engelleyici, caydırıcı faktör olmaktadır.

Rekabet ve firma performansı arasındaki ilişki Holmstrom (1982), Nalebuff ve Stiglitz (1983), Hart (1983) tarafından yapılan çalışmalarda ise vekâlet (asıl-vekil) modelleri çerçevesinde ele alınmaktadır. Rekabetin firma performansını pozitif yönde etkilediğini öngören bu modeller monopolistik rantların yöneticilere kaytarma olanağı verdiği düşüncesine dayanmaktadır (Nickell, Nicolitsas ve 
Dryden, 1997). Buna göre firma yöneticileri ve sahipleri arasında bilgi asimetrisi ve sübjektif risk mevcuttur. Firma performansını etkilediği düşünülen yeniliğe yönelik yatırımların da düşük efor harcama eğilimine sahip firma yöneticilerinin kararlarına bağlı olduğu varsayılmaktadır. Rekabet düzeyinin yönetici eforunu ve dolayısıyla firma performansını etkileyeceği düşünülmektedir. Şöyle ki yoğun rekabet yöneticilerin daha fazla efor göstermelerine ve dolayısıyla daha yüksek firma performansına neden olurken, rekabet baskısının düşük olduğu monopolistik piyasalar firma yöneticilerinin daha az efor göstermelerine, daha fazla kaytarmalarına ve dolayısıyla daha düşük firma performansına neden olmaktadir.

Vekâlet modelleri rekabet ve firma performansı ilişkisini rakip firma sayısının neden olduğu izleme kolaylığının yanı sıra iflas riskinin ve talep esnekliğinin rekabetçi ve monopolistik piyasalardaki farklılaşmasından hareketle de açıklamaktalar. Rekabet göstergesi olarak rakip firma sayısının dikkate alındığı modellerde, bu sayıdaki artışın hissedarlara firma veya yönetici performanslarını izleme ve değerlendirme konusunda daha fazla olanak sağladığı ve bilgi asimetrisini azatlığı düşünülür. Ayrıca rakip firma sayısının daha fazla olması cari performanslarına bağlı olduğu düşünülen gelecekteki ücret ödemeleri konusunda firma yöneticilerinin daha fazla endişe duymalarına neden olur. Bu durumun yöneticileri daha yüksek efor harcamaya zorlayacağı ve kaytarmayı azaltacağı düşünülür. Yönetici efor artışının da firma performansını artıracağı varsayılır. Bu nedenle rakip firma sayısı ile firma performansı arasında pozitif bir ilişki öngörülür (Rogers, 2004).

Daha yoğun rekabetin olduğu piyasalarda firmaların daha yüksek iflas riski taşımaları da beklenir. Bu nedenle rekabetçi piyasalarda yöneticilerin iflastan kaçınma için de daha yoğun efor göstermeleri gerekir ve bu piyasalarda kaytarmanın daha düşük oranlarda gerçekleşmesi beklenir. Bunun yanı sıra monopolistik özelliklerin yüksek olduğu piyasalarda talebin fiyat esnekliğinin daha düşük olması gerekir. Bunun sonucu olarak monopolistik özelliklerin yüksek olduğu piyasalarda fiyatların azalması satış gelirlerinin azalmasına neden olabilecektir. Dolayısıyla bu piyasalarda maliyetlerin azaltılması için yöneticiler güçlü güdülere sahip değildir. Talep esnekliğinin yüksek olduğu rekabetçi piyasalarda ise fiyat düşüşleri satış gelirlerini artırabileceğinden dolayı maliyetlerin azaltılmansa neden olacak üretkenlik artışı için yöneticilerin daha güçlü güdüleri vardır (Souare, 2013).

Schumpeteryen görüş ise rekabet yoğunluğu ve firma performans arasında daha farklı bir öngörüde bulunmaktadır. Buna göre üretkenliği ve firma performansını artıracak yatırımlar için gerekli kaynağın oluşturulması, kredi piyasası aksaklıkları dikkate alındığında önemli ölçüde firmaların geçmiş ve cari dönem karlarına bağlı olmaktadır. Bunun yanı sıra, gelecek dönemlere ilişkin kar beklentisi de bu tür yatırımlar için güçlü bir güdü sağlamaktadır. Daha fazla rekabet firma karlarını ve kar beklentilerini azalttığından yeniliği ortaya çıkartacak araştırmalar için 
ayrılması gereken kaynakların ve yenilik için gerekli teşviklerin azalmasına neden olmaktadır. Rekabet düşüklüğünün sunacağı monopolistik karların ise yenilik yaratmak için daha büyük kaynaklar ve teşvikler sunacağı düşünülmektedir (Rogers, 2004).

Schumpeteryen görüşe göre faaliyette bulundukları piyasada belirsizliğin düşük olmasından ve daha istikrarlı kaynaklara sahip olmalarından dolayı rekabet düzeyinin düşük olduğu endüstrilerde faaliyet gösteren firmalar daha istekli olabilirler. $\mathrm{Bu}$ noktada Schumpeteryen hipotez farklı şekillerde ifade edilebilmektedir. Bunlardan ilki 'yenilikçi faaliyetlerin büyük firmalarca desteklendiği' şeklinde ifade edilirken, diğeri 'yenilikçi faaliyetlerin daha çok piyasa yapısından yani aksak rekabet tarafından teşvik edildiğidir' (Kamien ve Schwartz, 1975; Levin, Cohen ve Mowery, 1985). Aghion, Bloom, Blundell, Griffith ve Howitt (2002) konuya ilişkin katkıları ise rekabet artışının yenilik ve üretkenliği pozitif ve negatif yönde etkileyebileceği, dolayısıyla ilişkinin ters ' $U$ ' biçiminde olabileceği şeklindedir. Buna göre tam rekabetçi veya monopol piyasa yapısına oranla orta düzeyde rekabetçi özellikler taşıyan piyasa yapısı yeniliğin ortaya çıkması için daha uygun koşullar sunmakta ve Schumpeteryen etki düşük rekabet düzeyinde değil yüksek rekabet düzeyinde ortaya çıkmaktadır.

Ar-ge faaliyetlerinin de ürün geliştirme, teknolojik ilerleme ve böylelikle firma performansı üzerinde belirleyici etkisinin olduğu düşünülebilir. Maliyetlerin azalmasına neden olacak yeni üretim tekniklerinin, tüketici zevk ve tercihlerine daha fazla hitap eden ürünlerin geliştirilmesi veya ürünlerin farklılaştırılması bu yönde bir efor gösterilmesini gerektirir. Başarılı bir şekilde sonuçlanan Ar-ge faaliyeti maliyet düşürücü gelişmenin yanı sıra ürün geliştirme veya ürün farklılaştırmasına, firmanın önemli bir piyasa pozisyonuna sahip olmasına veya pazar payını genişletmesine, rekabet üstünlüğü veya monopol gücü kazanmasına ve bu nedenle firma performansının artmasına neden olabilir. Düşük ar-ge yatırımları ise yeniliğin veya bilgi üretiminin azalmasına neden olur ki bu da nihayetinde üretkenlikte düşüşün yanı sıra fiziki ve beşeri sermaye yatırımlarında da azalmaya neden olur.

Ar-ge harcamalarının firma performansı üzerindeki pozitif etkisini vurgulayan Branch (1974), Tassey (1983), Jaffe (1986), Erickson ve Jacobson (1992) gibi çok sayıda çalışma olmasına karşın firmalar için ar-ge faaliyetlerini gerçekleştirmek nihayetinde maliyetli bir süreçtir. Bunun yanı sıra ar-ge faaliyetlerine yönelik harcamanın firma performansı üzerinde potansiyel pozitif etkisinin ortaya çıkması başarılı şekilde inovasyona dönüşmesine bağlıdır. Bu nedenle ar-ge harcamaları firma performans artışını garanti etmez. Fikri mülkiyet haklarının iyi şekilde korunmaması ve inovasyonun taklit edilmesi de ar-ge harcamalarının potansiyel faydasını azaltır. Bunun yanı sira ar-ge harcamalarının firma performansı üzerindeki etkisi genellikle Hartmann, Myers ve Rosenbloom'1n (2006) ifade ettikleri gibi gecikmeli ve orantılı olmayan şekildedir. Şöyle ki, ar-ge harcamalarının gerçekleşmesi ile nihai gelirlerin veya karların gerçekleşmesi 
arasındaki gecikme mevcuttur. Ayrıca, ar-ge harcamalarındaki artış orantılı kazanımlar sağlamaz. Buradan da anlaşıldığı gibi, Hartmann ve diğerlerinin (2006) ifade ettiği gecikme nedeniyle firma performansının başlangıçta olumsuz yönde etkilenmesi mümkündür. Kazanımların orantılı olmaması, azalan getiri ilkesinin yansıması olup daha yüksek ar-ge harcamalarının firma performansına aynı derecede yansımayacağını ifade eder.

Ar-ge harcamaları oranının aşırı derecede yüksekliğini ifade etmek için risk sermayedarları tarafından kullanılan bir kavram da batık oranıdır (burn rate) (McCutchen ve Swamidass, 1996). Batık oran ile aşırı derecede ar-ge harcamalarına katlanan firmaların bile piyasada rakiplerinin güçlü rekabeti ile karşılaşabilecekleri ifade edilmektedir. Rekabet üstünlüğünü rakiplere kaybetme ile karşı karşıya olan firmalar ar-ge faaliyetlerine kaynak harcayabilirler. Fakat rekabet yoğunluğu bu harcamaların performanslarına yansımasını engelleyebilmektedir.

\section{Araştırma Verisi ve Değişkenler}

Çalışmada Türk İmalat Sanayi NACE Rev.2 endüstri kollarının performans, inovasyon ve rekabet arasındaki ilişki ele alınmıştır. Analiz, yıllık verilerle gerçekleştirilmiş ve veriler Türkiye İstatistik Kurumu'nun www.tuik.gov.tr adresli internet sitesinden derlenmiştir. Çalışma veri seti inceleme dönemi olarak 20082013 dönemlerini kapsayan 6 yıldaki 24 imalat sanayii endüstri kolu için 144 gözlemden oluşmuştur. Türk İmalat Sanayi'nde firmaların dağılımlarına bakıldığında gıda, tekstil, metalik olamayan mineraller, giyim ve fabrikasyon metal ürünleri endüstrilerinde faaliyet gösteren firmaların toplam imalat sanayii firmalarının yarısından fazlasını oluşturmaktadır. Türk İmalat Sanayi'nde teknolojinin görece daha düşük düzeyde kullanıldığı ve daha geleneksel sanayi hâkimdir.

İnovasyonla işletme performansı arasındaki bağlantıyı ele alan çalışmalarda performans büyüme oranları (Freel, 2000; Verhees vd.,2010; Oh vd., 2015), karlıl1k oranları (Heunks, 1998; Freel, 2000; Forsman ve Temel, 2011) ve verimlilikle ifade edilmiştir (Huergo ve Jaumandreu, 2004; Kannebley vd., 2010; Forsman ve Temel, 2011). Çalışmada net kar marjı, öz sermaye karlılık oranı ve aktif karlılık oranı performans göstergeleri olarak ele alınmıştır.

İnovasyonu Schumpeter yeni veya geliştirilmiş ürünler, üretim teknikleri, organizasyon yapıları, yeni pazarların keşfi ve yeni girdi faktörleri olarak geniş biçimde tanımlamıştır. İnovasyon faaliyetlerinin ortak özelliği yeni ve farklı olmaktır (Forsman ve Temel, 2011). İnovasyon literatürde üç şekilde ölçülür. Bunlar; inovasyon girdi göstergeleri (ar-ge harcamaları, ar-ge personeli gibi), inovasyon ara çıktı göstergeleri (patentler, ticari markalar gibi) ve inovasyon çıktı göstergeleri (yenilik sayısı, yenilik türü, yenilik devir hızı gibi). Bu inovasyon göstergelerinden literatürde daha yoğun kullanılanları, girdi ve çıktı göstergeleridir. Literatürde inovasyonu girdi göstergeleriyle ölçen çalışmalar 
arasında Nassimbeni (2001), Özçelik ve Taymar (2004), Lopez, Rodriguez ve Garcia Rodriguez (2005), Wignaraja (2007), Harris ve Li (2009), D'Angelo (2012) ile Tsao ve Chen (2015) tarafinda yapılan çalışmalar gösterilebilir. İnovasyonu çıktı göstergeleriyle ölçenler arasında ise, Hitt vd. (1991), Pegels ve Thirumurthy (1996) ve Tsao ve Chen (2015) sayılabilir. Bu çalışmada inovasyon, bir girdi göstergesi olan ar-ge harcamalarıyla ölçülmüştür.

Piyasa yoğunluğu piyasa performansının bir parametresi veya göstergesi olarak kullanılmaktadır. Özellikle, Herfindahl-Hirschman İndeksi (HHI) piyasa rekabetinin değerlendirilmesinde bir dönüm noktası olarak kabul edilir (Sung, 2014). HHI, hem piyasadaki tüm firmaları hesaba katmasından, hem de firma sayısındaki azlık ve firma büyüklükleri arasındaki değişikliklere hassas olmasından dolayı daha yoğun biçimde kullanılmaktadır. HHI 0 ile 1 arasında değerler alabilmektedir. HHI piyasada tek bir firma varsa en yüksek değer olan 1'e ulaşır. Piyasada çok sayıda ve küçük ölçekli firmalar olduğunda indeks sıfıra yakın bir değer almaktadır. HHI $0-0,20$ arası ise düşük yoğunluklu ve tam rekabetçi bir piyasa; 0,20-0,40 arası ise orta yoğunluklu ve monopolcü rekabetçi bir piyasa; 0,40-1 arası ise yoğun ve rekabetçi olmayan oligopolcü bir piyasadan söz edilmektedir. Bu çalışmada HHI, rekabet göstergesi olarak modele katılmıştır.

Farklı endüstri kollarındaki firmaların farklı inovasyon stratejilerinin olabileceği ve bu farklı inovasyon stratejilerinin de performansa etkilerinin farklı düzeylerde olabileceğinden (Oh vd., 2015) hareketle performans modeline endüstri teknoloji yoğunluğu kukla değişkenleri dâhil edilmiştir. Endüstri teknoloji yoğunluğu NACE Rev.2 temelinde düşük, orta-düşük, orta-yüksek ve ileri teknoloji kukla değişkenleriyle belirlenmiştir. Böylece, endüstrilerdeki teknoloji seviyelerinin performansa etkileri ortaya konmuştur. Ayrica, modelde sermaye ve emek faktörlerini temsilen kontrol değişkenleri olarak iki bağımsız değişken yer almıştır.

\section{Araştırma Tahmin Yöntemi}

Panel veri analizi temel tahmin yöntemi Havuzlanmış En Küçük Kareler (HEKK) olmasına rağmen hata terimi ve bağımsız değişkenler arasında ilişkinin varlığında ve zaman içinde hata teriminde ardışık bağımlılık olduğunda HEKK ile tutarlı tahminler elde edilemez (Wooldrige, 2002: 256). Söz konusu bu sakıncaların giderilmesi amacıyla statik ve dinamik olan panel veri analizi için özel tahminciler geliştirilmiştir.

Statik panel veri yöntemlerinde, esasen cari dönemde oluşan iktisadi ve ticari davranışların geçmiş deneyim ve davranışlardan bağımsız olduğu fikri yatmaktadır. Bu geçmiş deneyim ve davranışları dikkate alındığında analize dinamik bir nitelik kazandırılmaktadır. Bunu dikkate alan panel veri yöntemleri dinamik panel veri modellerdir. Bu yönüyle dinamik panel veri analizi, yatay kesit veya zaman serisi yöntemlerinin ortaya koyamadığı, mikro ve makro dinamikleri ortaya koyabilmektedir (Bond, 2002: 1). 
Dinamik panel veri analizi, ekonometri literatüründe, ilk olarak Hansen (1982) tarafından geliştirilmiş olan Genelleştirilmiş Momentler Metodunu (GMM) temel almaktadır. Anderson ve Hsiao (1981 ve 1982) GMM'yi panel veriye uyarlamışlardır. Daha sonradan Arellano ve Bond (1991), Arellano ve Bover (1995) ve Blundell ve Bond (1998) tarafindan bu yöntem geliştirilmiş ve panel veri yazınında yazarların isimleriyle birlikte anılan GMM ve Sistem Genelleştirilmiş Momentler Metodu (SGMM) olarak geçmiştir.

GMM tahmin yönteminde öncelikle modelin birinci farkı alınıp, fark modelin araç değişken matrisi kullanılarak dönüştürülmektedir. Daha sonra dönüştürülmüş model Genelleştirilmiş En Küçük Kareler (GEKK) ile tahmin edilmektedir. Veri seti dengeli olmayan panel veri ya da birim sayısının zamandan az olduğu panel verilerde birinci fark dönüşümü zayıf kalmaktadır. Bu durumda doğrusal (orthogonal) sapmaları kullanan SGMM kullanılmaktadır. Böylece SGMM ile etkin araç değişken tahmincisi elde edilebilmektedir (Baltagi, 2005: 148). SGMM'de GMM deki cari dönemden bir önceki dönemin farkının alınması yerine, değişkenlerin tüm olası gelecek değerlerinin ortalamalarının farkı alınmaktadır. Böylece, birinci farklar yönteminden kaynaklanan veri kaybı en aza indirilmektedir (Blundell ve Bond, 2000).

GMM tahmin yöntemi zamanın birim sayısından daha fazla olduğu panel veri setindeki değişkenler arası ilişkilerin tahmininde tercih edilmektedir. Dolayısıyla, birimin zamandan büyük olduğu panel veri setlerinde değişkenler arasındaki doğrusal ilişkinin ortaya konmasında da SGMM tahmin yöntemi tercih edilir. GMM ve SGMM'nin iki aşamalı tahmincileri de mevcuttur. Bağımsız değişkenlerin içsel değişken olduğu durumda iki aşamalı tahminlerden elde edilen bulgular daha tutarlı ve sapmasızdır. Bu çalışmanın veri setinde birim sayısı zamandan büyük olduğundan Arellano ve Bover (1995) ve Blundell ve Bond (1998) tarafindan önerilen İki Aşamalı SGMM tahmin yöntemi ile tahminler gerçekleştirilmiştir. Ayrıca küçük örneklem tahminlerindeki standart hataların sapmasız olması için Windmeijer'in (2005) tarafından önerilen dirençli standart hatalar kullanılmıştır. Söz konusu dirençli standart hataların hesaplanmasında Roodman (2009) tarafından yazılan kod kullanılmıştır.

Çalışmada performans modelleri dinamik panel veri analiz yaklaşımıyla tahmin edilmiştir. İlgili ilişki aşağıdaki denklemde gösterilmiştir:

$$
\begin{aligned}
& \sum_{j=1}^{k} \text { PERFORMANS }_{i t} \\
& =\beta_{1} \sum_{j=1}^{k} \text { PERFORMANS } S_{i t-1}+\beta_{2} S E R M A Y E_{\mathrm{i} t}+\beta_{3} E M E K_{\mathrm{i} t} \\
& +\beta_{4} A R G E Y O \breve{G} U N L U \breve{G} U_{\mathrm{It}}+\beta_{5} A R G E Y O \breve{G} U N L U \breve{G} U_{\mathrm{It}-1}+\beta_{6} H H I_{\mathrm{I} t} \\
& +\beta_{7} \sum_{i=1}^{m} K T E K N O L O J \grave{1}_{i t}+\varepsilon_{i t} \\
& i=1,2, \ldots, 24 \quad j=1,2 \text { ve } 3 \quad l=1,2 \text { ve } 3 \quad t=2008, \ldots, 2013
\end{aligned}
$$


1 numaralı denklemde, $i$, $t$, $j$ ve $l$ sirasiyla endüstri kolu, zaman, performans göstergesi ve teknoloji düzeyini ifade etmektedir. Denklemdeki PERFORMANS $_{\text {it-1 }}$ modele dinamik özellik katan bağımlı değişkenin bir dönem gecikmesidir. $\sum_{j=1}^{k}$ PERFORMANS $S_{i t} \mathrm{t}$ dönemi endüstri kolu performansı olan öz sermaye karlılık oranı, aktif karlılık oranı ve net kar marjını, $\sum_{j=1}^{k}$ PERFORMANS $_{i t} \mathrm{t}-1$ dönemi endüstri kolu performans1 olan öz sermaye karlıl1k oranı, aktif karlılık oranı ve net kar marjını, SERMAYE $E_{i t} \mathrm{t}$ dönemi endüstri kolu maddi duran varlık toplam aktif oranını, $E M E K_{t} \mathrm{t}$ endüstri kolu çalışan sayısını, ARGE YOĞUNLUĞ $U_{\text {it }} \mathrm{t}$ dönemi endüstri kolu ar-ge yatırımının toplam aktife oranını, ARGE YOĞUNLUĞ $U_{\text {it-1 }}$ t-1 dönemi endüstri kolu ar-ge yatırımının toplam aktife oranını $\sum_{l=1}^{m} K T E K N O L O J I_{i t}$ dönemi endüstri kolu teknoloji yoğunluk düzeyi kukla değişkenlerini, $H H I_{\mathrm{It}} \mathrm{t}$ dönemi endüstri rekabet yoğunluğu değişkeni ve $\varepsilon_{i t}$ denklemin hata terimini göstermektedir.

\section{Araştırma Bulguları}

Araştırmanın bulguları endüstrilerin genel özellikleri ve model değişkenleri arasındaki ilişkilerin sunulduğu tanımlayıcı istatistikler, korelasyonlar, eğilimler, birim kök testi ve panel veri analiz tahmin sonuçları aşağıda sunulmuştur.

\subsection{Tanımlayıcı İstatistikler ve Korelasyonlar}

Aşağıdaki Tablo 1'de araştırmanın değişkenlerin ortalama ve standart sapmaları olarak tanımlayıcı istatistikleri yer almaktadır. Tablo 1'de çalışmanın bağımlı ve bağımsız değişkenlerinin ortalama ve standart sapma değerleri sunulmuştur. İnceleme döneminde Türkiye'deki imalat sanayiinde performans göstergeleri olan net kar marjı, aktif karlılık oranı ve öz sermaye karlılık oranının \%3 ile \%9 arasında düşük düzeyde gerçekleşmiştir. İktisadi açıdan sermaye olan maddi duran varlıkların toplam aktif içerisindeki payı imalat sanayiinde ortalama $\% 27$ 'dir. $\mathrm{Bu}$ bulgu toplam aktifin yaklaşı \%27'si düzeyinde fiili üretim kapasitesine sahip olunduğunu göstermektedir. Buna ilave olarak, endüstrilerin ortalama istihdamının 40.000'inin üzerinde, ar-ge yatırımının aktifin sadece \%1'i civarında ve orta yoğunlukta monopolcü rekabetçi bir piyasa olduğu görülmektedir. Dolayısıyla, imalat sanayinde sermayenin ve rekabetin orta düzeyde, buna rağmen performansın, ar-ge yoğunluğunun ve istihdamın görece düşük olduğu ortaya çıkmaktadır.

Tablo 1: Değişkenlerin Tanımlayıcı İstatistikleri

\begin{tabular}{|l|l|l|}
\hline Değişkenler & Ortalama & Standart Sapma \\
\hline Net Kar Marjı (\%) & 3,69 & 4,80 \\
\hline Aktif Karlılık Oranı (\%) & 3,65 & 4,04 \\
\hline Öz Sermaye Karlılı Oranı (\%) & 8,49 & 9,49 \\
\hline Ar-ge Yoğunluğu (\%) & 1,16 & 3,48 \\
\hline Emek (Kişi) & 41.573 & 40.634 \\
\hline Sermaye (\%) & 26,89 & 8,32 \\
\hline HHI $(0 \leq \mathrm{HHI} \leq 1)$ & 0,226 & 0,213 \\
\hline
\end{tabular}


Tablo 2'ye göre imalat sanayinde aslında düşük ve orta-düşük teknolojilerin hâkimiyeti söz konusudur. Teknoloji yoğunluğunun yüzde dağılımı incelendiğinde imalat sanayii içinde yüksek teknoloji endüstrileri sadece \%8'dir. Teknoloji yoğunluğu firma dağılımına göre irdelendiğinde yüksek teknoloji firma yüzdesi daha da düşüktür.

Tablo 2: Endüstrilerin Teknoloji Yoğunluk Düzeyi Frekansları

\begin{tabular}{|l|l|l|l|l|}
\hline $\begin{array}{l}\text { Teknoloji Yoğunluk } \\
\text { Düzeyi }\end{array}$ & Endüstri Sayıs1 & Endüstri \% & Firma Sayıs1 & Firma \% \\
\hline Düşük Teknoloji & 11 & 45,9 & 10.081 & 49.3 \\
\hline Orta-Düşük Teknoloji & 6 & 25,0 & 5.852 & 28.7 \\
\hline Orta-Yüksek teknoloji & 5 & 20,8 & 4.059 & 19.9 \\
\hline Yüksek Teknoloji & 2 & 8,3 & 438 & 2.1 \\
\hline Toplam & 24 & 100 & 20.430 & 100 \\
\hline
\end{tabular}

Bu bilgiler Türk İmalat Sanayi'nde düşük ve orta düzey teknoloji yoğunluğunun egemen olduğunu göstermektedir. İmalat sanayiinde görece katma değeri ve rekabet gücü daha düşük olan endüstriler ağırlıktadır. Teknoloji yoğunluğundaki yüksek teknoloji lehine politikalar geliştirilirken firma dağılımının iyileştirilmesi gerekliliği ön plana çıkmaktadır. Bu iyileşmelerin ardından imalat sanayiinde katma değeri daha yüksek çıktılarla birlikte endüstri performanslarında artışlar sağlanabilecektir.

Tablo 3: Korelasyon Katsayıları

\begin{tabular}{|l|l|l|l|l|l|l|}
\hline Değişkenler & NKM & AKO & ÖSKO & Sermaye & Emek & Ar-ge Y. \\
\hline NKM & 1 & & & & & \\
\hline AKO & $0,880^{* * * *}$ & 1 & & & & \\
\hline ÖSKO & $0,827^{* * * *}$ & $0,951^{* * * *}$ & 1 & & & \\
\hline Sermaye & $-0,215^{* *}$ & $-0,215^{* * *}$ & $-0,254^{* *}$ & 1 & & \\
\hline Emek & 0,052 & $0,099^{*}$ & 0,056 & $0,118^{* *}$ & 1 & \\
\hline Ar-ge Yoğunluğu & $0,146^{* *}$ & 0,028 & $0,118^{* *}$ & $-0,466^{* * *}$ & $-0,110^{*}$ & 1 \\
\hline HHI & 0,026 & 0,100 & $0,144^{*}$ & 0,021 & $-0,156^{*}$ & $-0,082$ \\
\hline
\end{tabular}

Not: ${ }^{*}{ }^{* *}$ ve ${ }^{* * *}$ sirasiyla $0.10,0.05$ ve 0.01 düzeyinde istatistiksel anlamlılıkları göstermektedir.

Tablo 3'de değişkenlerin korelasyonları sunulmuştur. Performans değişkenleri arasındaki korelasyon beklendiği üzere yüksektir. Performans ile sermaye dışındaki bağımsız değişkenler arasındaki korelasyon pozitiftir. Sermaye değişkeni olan maddi duran varlıkların toplam aktife oranı ile performans değişkenleri arasındaki korelasyonun negatif olması maddi duran varlıklara yapılan yatırımın karlılığı azalttığı anlamına gelmektedir. $\mathrm{Bu}$, beklenen bir bulgudur. Çünkü maddi duran varlıklara yapılan yatırım karın azalmasına neden olur. Bu azalma iç finansmana başvurulduğunda karın doğrudan maddi duran varlıklara yatırılmasıyla, diş finansmana başvurulduğunda ise borcun anapara ve faiz ödemesiyle gerçekleşecektir. Emeğin performansla pozitif korelasyonu emekteki verimlilik artışından kaynaklanmaktadır. Ar-ge yoğunluğunun performansla pozitif korelasyonu, yeniliğin verimlilik artışına neden olduğu 
biçiminde yorumlanabilir. Endüstri rekabet düzeyi ile performans arasındaki pozitif korelasyon rekabet yoğunluklu ile performansın doğrusal yönde ilişkide olduğunu ifade etmektedir. Dolayısıyla imalat sanayinde rekabetin düşük olduğu yoğunlaşmış endüstrilerde daha yüksek performansın varlığından söz edilebilir.

\subsection{Değişkenlerin Eğilimleri}

Grafik 1-3'te çalışma değişkenlerinin inceleme döneminde gösterdiği eğilimler sunulmuştur.

Grafik 1: Performans Göstergeleri \%

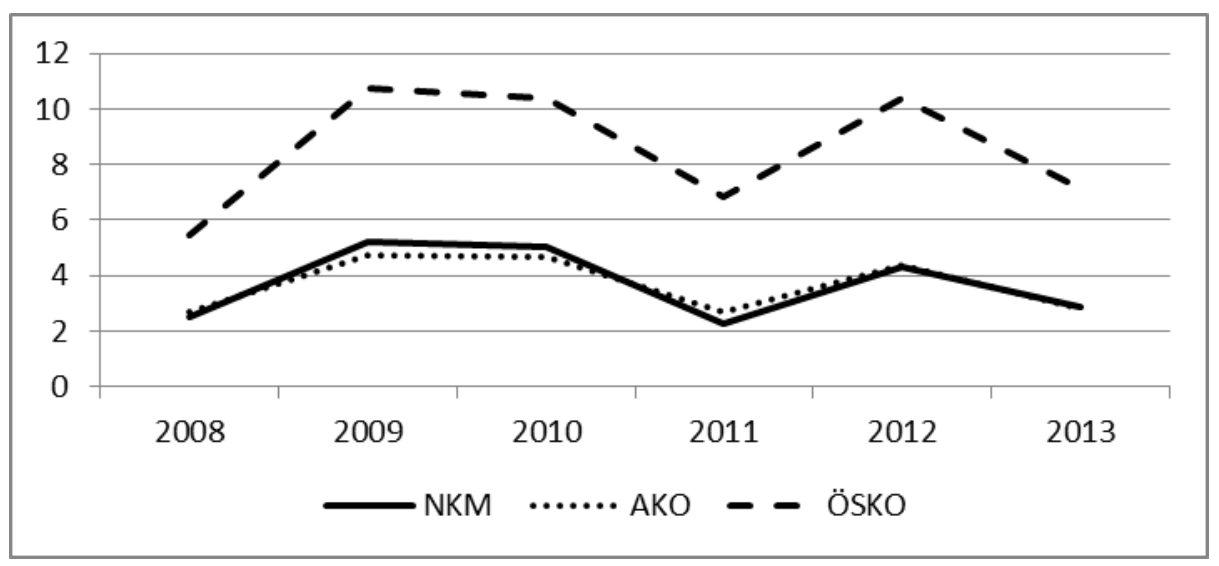

Grafik 1'de Türk İmalat Sanayi'nin yıllar itibariyle performansı verilmiştir. Tüm performans göstergelerinin benzer seyir izlediği tespit edilmektedir. Bu seyir "ters W" şekline benzetilebilir. Performans göstergeleri sırasıyla 2009, 2010 ve 2012 yıllarında yükselmiş, buna karşın 2008 ve 2011 yıllarında düşmüştür. Dolayısıyla performansta dalgalanmalar olmuş, yıllar itibariyle inişler ve çıkışlar birbirini izlemiştir. $\mathrm{Bu}$ bulgu, inceleme döneminde Türkiye'deki İmalat Sanayii'nin istikrasız, yani değişken bir performansa sahip olduğunu gösterir. Bunun daha çok, küresel ekonomide yaşanan finansal krizden kaynaklandığını söylemek yanlış olmayacaktır.

Grafik 2'de ifade edildiği gibi Türk İmalat Sanayi'nin ar-ge yoğunluğunda aynı düzeyde olmasa bile sürekli bir artış vardır. 2008 yılında ar-ge yoğunluğu neredeyse sıfırdır. Bunu takip eden yıllarda ar-ge yoğunluğu artarak yaklaşık \%1,6 seviyesine gelmiştir. Gelinen seviye düşük olmasına rağmen, bu hızlı artış hükümetin sektörel ve bölgesel kalkınma politikalarının yanında teknoloji yatırımlarına verdiği teşviklerin sonucu olduğu söylenebilir. 
Grafik 2: Ar-ge Yoğunluğu (\%)

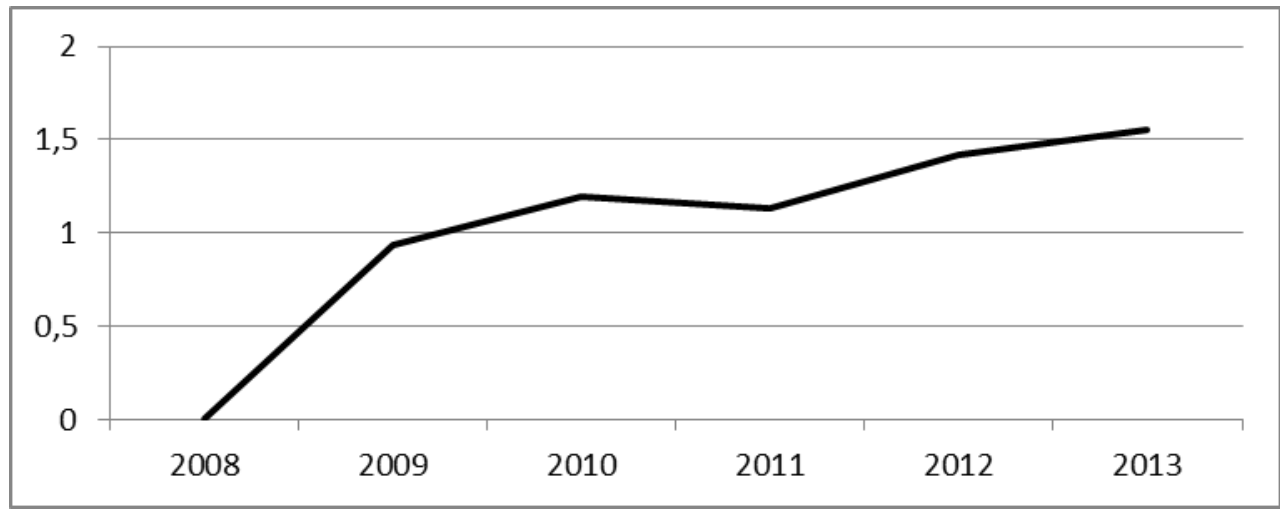

Grafik 3'te Herfindahl-Hirschman İndeksi (HHI) ile hesaplanmış endüstri rekabet yoğunluğunun 2009-2012 y1lları için ortalamaları sunulmuştur. HHI belirtilen yıllarda $0,20-0,40$ aras1 değer aldığ1 ve orta yoğunluğa sahip olduğu görülmektedir. HHI'deki düzenli düşüş ise, imalat sanayiinde yoğunluğun azaldığını yani rekabetin gittikçe arttığını göstermektedir. Türk İmalat Sanayii 2009'da düşük rekabetçi bir yapıya sahipken, 2012'de nispeten daha rekabetçi bir görünüm kazanmıştır.

Grafik 3: Endüstri Rekabet Yoğunluğu (HHI)

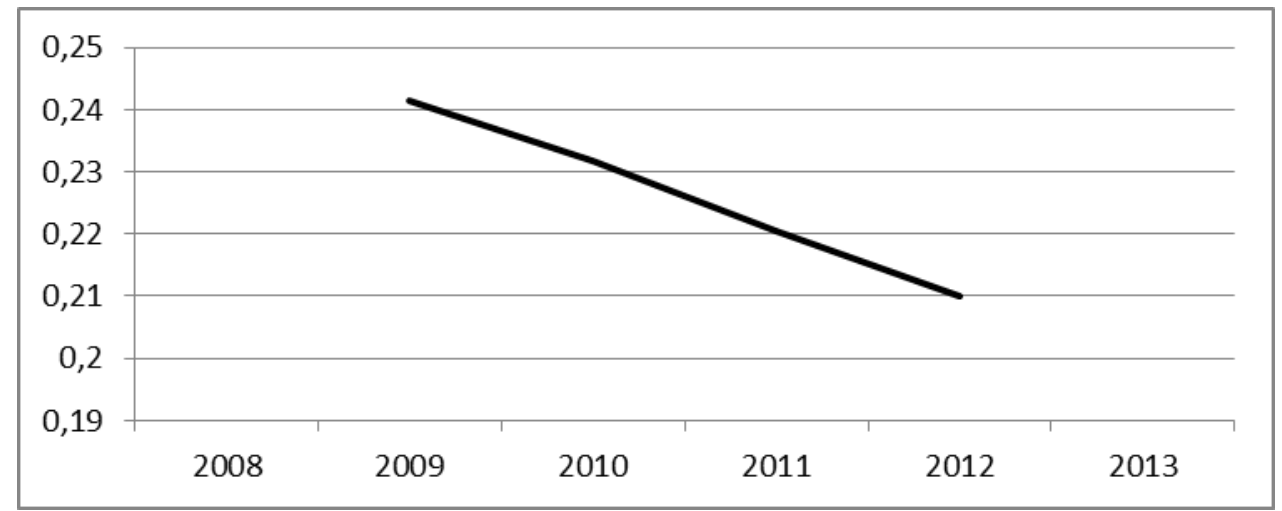

\section{3. Panel Birim Kök Testi}

Zaman serilerinde olduğu gibi panel verilerin tahmininde de sahte regresyonla karşılaşmamak için öncelikle değişkenlerin birim kök testleri aracılığıyla durağanlıkları tespit edilmektedir. Panel veriler için geliştirilmiş panel veriye özgü birim kök testleri mevcuttur. Panel veri birim kök testleri, birimler aras1 korelasyonun bulunup bulunmamasına göre iki gruba ayrılırlar. Birimler aras1 korelasyonun bulunmadığında birinci, bulunduğunda ise ikinci kuşak testler aracılığıyla durağanlık sınanır. Başka bir deyişle, birinci kuşak panel birim kök testleri birimlerin bağımsız olduğunu, ikinci kuşak panel birim kök testleri ise birimlerin bağımlı olduğunu varsaymaktadır. Birinci kuşak panel birim kök testleri, kendi içerisinde iki kısıma ayrılırlar. Bunlardan, ilk gruptakiler 
otokorelasyonun birimden birime değişmediğini varsayan birinci grup diğeri ise değiştiğini varsayan ikinci gruptur. Dolayısıyla ilk gruptakiler ortak otokorelasyon, ikinci gruptakiler ise bireysel otokorelasyon varsayımı dahilinde hesaplanırlar. İkinci kuşak birim kök testler kendi içerisinde üç grupta düşünülebilir. Ilk gruptakiler, birinci kuşak panel birim kök testlerinin çeşitli dönüşümlerle birimler arası korelasyonu dikkate alarak biçimde düzeltilmesiyle oluşturulmuştur. İkinci gruptaki testler, Görünüşte İlişkisiz Regresyon (SUR) tipi sistem tahminlerine dayanan panel birim kök testleridir. Üçüncü gruptakiler ise, birimler arası korelasyonun ortak faktörler yardımıyla modellendiği panel birim kök testleridir (Yerdelen Tatoğlu, 2017, 67). Birinci gruptaki panel birim kök testlerindeki dönüşümlerin birimler arası korelasyonu azaltmasına karşın, bazı korelasyon tiplerini tamamen yok edememesi nedeniyle literatürde çok fazla tercih edilmemekte, ikinci ve üçüncü gruptakiler daha fazla rağbet görmektedir.

Panel birim kök testinin hesaplanmasına geçmeden önce hangi tür birim kök testleriyle durağanlığın incelenmesinin uygun olacağına karar verilmesi amaciyla birimlerin bağımsızlığının tespiti gerekir. Çalışmada birimlerin bağımsızlı̆̆ birim sayıs1 zamandan fazla olduğundan Pesaran (2004) CD testi ile birimlerin bağımsızlığı sınanmıştır. Pesaren (2004) birimlerin bağımsızlığı testi sonuçları aşağıda Tablo 4'de sunulmuştur.

Tablo 4: Birimlerin Bağımsızlığı Testi

\begin{tabular}{|l|l|l|}
\hline Değişkenler & Pesaran CD Testi & Korelasyon \\
\hline NKM & $11,48^{* * *}$ & 0,282 \\
\hline AKO & $8,87^{* * *}$ & 0,218 \\
\hline ÖSKO & $8,32^{* * *}$ & 0,204 \\
\hline Sermaye & $5,18^{* * *}$ & 0,127 \\
\hline Emek & $3,74^{* * *}$ & 0,108 \\
\hline Ar-ge Yoğunluğu & $13,34^{* * *}$ & 0,328 \\
\hline HHI & $-0,006$ & $-0,002$ \\
\hline
\end{tabular}

Not: ${ }^{*},{ }^{* *}$ ve ${ }^{* * *} 0.10,0.05$ ve 0.01 düzeyinde istatistiksel anlamlılıkları göstermektedir.

Tablo 4'de HHI dışındaki değişkenlerin birimler arasında korelasyona sahip olduğu yani birimlerin bağımlı olduğu ortaya çıkmıştır. HHI değişkeninde birimlerin bağımsız olduğu görülmüştür. Korelasyonlar pozitiftir ve en yüksek olanların ar-ge ile ardından karlılık oranlarının takip ettiği tespit edilmiştir. Buradan endüstri kollarında inovasyon ve karlılıkların bağımlılığın yüksek olduğu, yani endüstri kollarının birbirlerine bağımlı olduğu sonucu çıkarılabilir. Durağanlık analizinde HHI değişkeni birinci kuşak diğer değişkenler ise ikinci kuşak panel birim kök testleriyle test edilmesine karar verilmiştir.

Çalışmanın birimleri imalat sanayiindeki sektörler olduğundan farklı sektörlerde yapılan işin doğası gereği farklılaşacağı kabulünden hareketle otokorelasyonun birimler için değişeceği varsayımının daha isabetli olacağına karar verilmiştir. Böylece HHI değişkeninin birinci kuşak panel birim kök testlerinden ikinci grup 
testlerle analizi uygun görülmüştür. İkinci grup panel birim kök testlerinden küçük örneklemle daha elverişili olduğundan Fisher testleri tercih edilmiştir. Fisher testleri Fisher ADF ve Fisher Philips-Perron (PP) olmak üzere iki şekilde uygulanmaktadır. HHI değişkeninin durağanlığı Fisher Philips-Perron (PP) birim kök testiyle gerçekleştirilmiştir. Diğer değişkenlerin durağanlık testi amacıyla ikinci kuşak birim kök testlerin üçüncü grubunda yeralan Pesaran (2007) CIPS birim kök testi kullanılmıştır. Durağanlık test sonuçları aşağıdaki Tablo 5'de sunulmuştur.

Tablo 5: Değişkenlerin Durağanlık Testleri

\begin{tabular}{|l|l|l|}
\hline Değişkenler & Pesaran CIPS Testi & Düzeltilmiş Ters $X^{2}$ \\
\hline NKM & $-2,240^{* *}$ & - \\
\hline AKO & $-2,269^{*}$ & - \\
\hline ÖSKO & $-2,335^{* *}$ & - \\
\hline Sermaye & $-2,390^{* *}$ & - \\
\hline Emek & $-2,230^{*}$ & - \\
\hline Ar-ge Yoğunluğu & $-2,343^{* *}$ & - \\
\hline HHI & - & $36,880^{* * *}$ \\
\hline
\end{tabular}

Tablo 5'te Fisher P-P testinin $\mathrm{P}, \mathrm{Z}, \mathrm{L}^{*}$ ve $\mathrm{P}_{\mathrm{m}}$ istatistiklerinin tamamı aynı sonucu verdiğinden bunlardan sadece $\mathrm{P}_{\mathrm{m}}$ istatistiğini gösteren Düzeltilmiş Ters $X^{2}$ değerleri raporlanmıştır. Tablo 5'deki bulgulara göre HHI değişkeni Fisher Phillips-Perron testi ve diğer değişkenlerin Pesaran CIPS birim kök testi sonucunda birim kök içermediği sonucuna ulaşılmıştır. Bu bulgular değişkenlerin tamamının düzey durağan olduğu göstermiştir. Bu sonuçtan hareketle performans modeli durağan olunan düzeyde aşağıda analiz edilmiştir.

\subsection{Performans Modeli Bulguları}

Performans modellerinde elde edilen bulgular aşağıdaki Tablo 6'da sunulmuştur. Modellerin genel anlamlılı̆̆ını sınamak için yapılan Wald İstatistikleri'ne göre modeller anlamlıdır. Modellerle ilgili, birinci mertebe otokorelasyonun varlığının testinde Arellano ve Bond'un otokorelasyon (AR1) testi anlaml ve ikinci mertebe otokorelasyon (AR2) testi anlamsızdır. $\mathrm{Bu}$ testlere göre, modellerde birinci mertebe otokorelasyonun olduğu buna karşın, ikinci mertebe otokorelasyonun olmadığı bulunmuştur. $\mathrm{Bu}$ bulgu, modellerdeki bağımsız değişkenlerin ikinci gecikmeleri olan araç değişkenlerin doğru tespit edildiği anlamına gelmektedir. Ardından, modellerden elde edilen araç değişkenlerin geçerliliği için yapılan dirençsiz Sargan Testi anlamlı iken, dirençli Hansen Testi ve dirençli Fark Hansen Testi anlamsızdır. Dirençsiz Sargan Testi dışındaki dirençli testler, performans modellerinin tahmininde kullanılan araç değişkenler regresyonunda kullanılan araç değişkenlerin geçerli ve modellerin uygun olduğunu göstermektedir. Sonuçta, 
modellerin genel anlamlılık, otokorelasyon ve araç değişkenler regresyonu ile ilgili koşulları sağladığı söylenebilir.

Tablo 6'daki performans modellerinin tamamında endüstri performansına endüstri performansının bir dönem gecikmesinin pozitif ve anlamlı etkisi vardır. Bu etki öğrenmenin ve deneyimin olum katkısının incelenen dönemde çalıştığı anlamına gelir. Tablodan sermayenin performans göstergelerinden sadece net kar marjına pozitif ve anlamlı etkisinin olduğu, diğer performans göstergeleri olan aktif karlılık oranı ve öz sermaye karlılık oranına etkisinin ise anlamlı olmadığı tespit edilmiştir. Bununla birlikte, Emeğin performans göstergelerinin tamamına etkisi pozitif ve anlamlıdır. Emek ve sermayenin performans üzerindeki bu etkileri, emeğin sermayeye kıyasla veriminin yüksek olduğu ve maliyetlerdeki göreli azaltılmayla performansı artırdığı anlamına gelebilir.

Tablo 6: Performans Modelleri Sonuçları

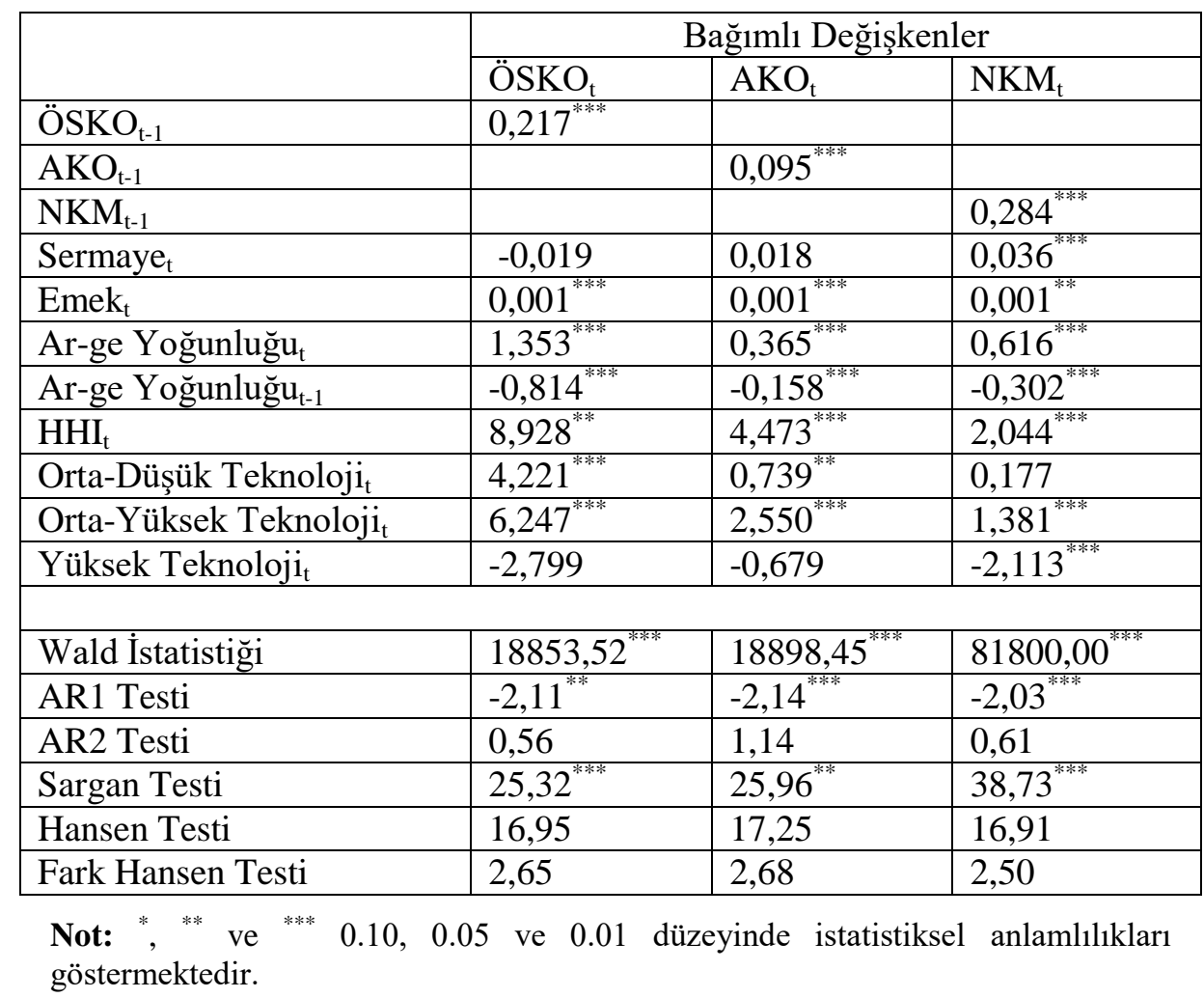

Ar-ge yoğunluğunun performansa etkisi pozitif, ar-ge yoğunluğunun bir dönem gecikmesinin performansa etkisi ise negatiftir. Cari dönem yeniliği cari dönem performansını artırmasına rağmen, ar-genin bir dönem gecikmesi azaltmaktadır. Söz konusu ar-ge yatırımları endüstri performansını yükselttiği, bir dönem önceki ar-ge yatırımları dolayısıyla ortaya çıkan ticari faydanın ise rakipler tarafından taklit edilip rekabet avantajının yani farklılığın ortadan kalktı̆̆ 1 görülmektedir. 
Endüstri kolu rekabet düzeyini gösteren rekabet yoğunluğu (HHI) değişkeninin performansa etkisi pozitiftir. Endüstri rekabetinin daha düşük olduğu aksak rekabete sahip endüstrilerde performans daha yüksek gerçekleşmiştir. Dolayısıyla, Türkiye İmalat Sanayinde endüstrilerde tam rekabetçi piyasadan rekabetçi monopolcü piyasaya oradan da rekabetçi oligopolcü piyasaya geçildikçe performansı arttı̆̆1 ortaya konmuştur. Türkiye İmalat Sanayinde rekabetin performansa etkisi Schumpeteryen görüş öngörüsünü destekleyici niteliktedir.

Son olarak endüstrilerin teknolojik yoğunluk düzeylerini gösteren üç teknoloji kukla değişkeninin performans göstergelerine etkilerinin hem pozitif hem de negatiftir. Orta-düşük düzey teknolojiyi gösteren teknoloji kukla değişkeninin öz sermaye karlılık oranı ve aktif karlılık oranına etkisi pozitif ve anlamlıdır. Ortayüksek düzey teknolojiyi gösteren teknoloji kukla değişkeninin performans göstergelerinin tamamına pozitif ve anlamlı etkisi vardır. Yüksek yoğunlukta teknolojiyi ifade eden teknoloji kukla değişkenin ise, sadece net kar marjına etkisi anlamlı ve negatiftir. Teknoloji yoğunluklarının performansa etkisi Oh vd. (2015) tarafından Kore firmaları bulguları ile örtüşmektedir. Firma sayısının çoğunlukta olduğu düşük ve orta düzey teknoloji yoğunluğuna sahip endüstrilerde teknoloji performansı artırırken, buna karşın ileri teknoloji endüstrilerinde azaltmıştır.

\section{Sonuç ve Öneriler}

İktisat teorisinde inovasyon ve rekabetin performans üzerinde etkisini açıklayan yaklaşımlar birbirileri ile farklılık gösterir. Neo-klasik iktisadi görüşe göre, rekabetçi piyasalarda firmalar sahip oldukları kaynakları etkin şekilde kullanma yönünde güçlü güdülere sahip olduklarından bu piyasalarda firma performansı karşılaştırmalı olarak daha yüksektir. Schumpeteryen görüşte ise rekabet firma karını veya kar beklentisini azalttığı için inovasyonu ortaya çıkartacak faaliyetler için ayrılması gereken kaynakları ortadan kaldırma yönünde etki eder. Bu nedenle rekabet yoğunluğu inovasyonu ortaya çıkarmak için gerekli teşviklerin azalmasına neden olur. Düşük rekabetten kaynaklanan monopolistik karların ise inovasyon yaratmak için daha büyük kaynaklar sağlayacağı ve teşvikler sunacağı düşünülmektedir.

Çalışmada, Türk İmalat Sanayi'nin dalgalı bir performansa ve düşük seviyede olmasına rağmen giderek yükselen ar-ge yatırımlarına, düşük fakat giderek artan bir rekabet yapısına, üretim teknolojisinin ise çoğunlukla düşük ve orta yoğunluk düzeyine sahip olduğu tespit edilmiştir.

Ar-ge ve karlılık oranları için birimler arası korelasyonun yüksek olduğu tespit edilmiştir. Buradan endüstrilerin inovasyon ve kar açısından birbirlerine bağımlı olduğu söylenebilir.

Değişkenlerin tamamının düzey durağan olduğu bulunmuştur. $\mathrm{Bu}$ değişkenlerin uzun dönemde bir değere yaklaştığ 1 ya da beklenen değer etrafında değerler aldığı anlamına gelir. Buradan ar-ge, karlılık oranları, rekabet, sabit sermaye ve 
istihdamın uzun dönem ortalamasına yakın seyrettiğini söylemek yanlış olmayacaktır.

Panel veri analizi sonuçlarına göre emek endüstri performansını artırıcı yönde etkilemektedir. Ar-ge yoğunluğunun performansı artırdığı, bir dönem önceki arge'nin ise Hartmann vd., (2006)'nin belirttiği gibi performansı azalttığ1 görülmüştür. Gecikmeli etkinin negatif olması inovasyonun rakipler tarafindan taklit edilmesi ve elde edilen rekabet avantajının ortadan kalkmasından kaynaklanabilir. Bu bulgu Arrow'un (1962), buluşların uygun telif hakkı ödenerek ticarileştirilmesi ve fikri mülkiyet haklarının korunması uyarısının Türk İmalat Sanayiinde tam olarak sağlamadığını göstermektedir. Sonuç olarak, yüksek maliyet gerektiren inovasyon yatırımlarının radikal ve sürekli şekilde cesaretlendirilmesi amacıyla merdiven altı veya taklit üretimin etkin biçimde önlenmesi gerekliliği ortaya çıkmaktadır.

Rekabetinin daha düşük olduğu endüstrilerde performans daha yüksek gerçekleşmiştir. Bu bulgu, Türk İmalat Sanayii için Schumpeteryen görüşü destekleyici niteliktedir. Schumpeteryen görüşe göre rekabet düzeyinin düşük olduğu piyasalarda faaliyette bulunan firmalar daha istikrarlı kaynaklara sahip olduklarından dolayı daha başarılı olabilirler. Daha fazla rekabet firma karlarını ve kar beklentilerini azalttığından inovasyonu ortaya çıkartacak araştırmalar için ayrılması gereken kaynakların ve inovasyon için gerekli teşviklerin azalmasına neden olmaktadır.

Teknoloji yoğunluğunun performansa etkisi ise tek düze değildir. Çalışma bulguları orta düzey teknolojinin performansı pozitif, yüksek teknolojinin ise negatif yönde etkilediğini göstermektedir. Teknoloji yoğunluklarının performansa etkisi Oh vd. (2015) tarafından Kore firmalarına ilişkin yapılan çalışmanın bulguları ile örtüşmektedir. Firma sayısının çok olduğu düşük ve orta düzey teknoloji yoğunluğuna sahip endüstrilerde teknolojinin performansı artırdığ1, buna karşın yüksek teknoloji endüstrilerinde azalttığı görülmüştür. Burada kritik olan, ileri teknoloji endüstrilerinin ve bu endüstrilerde faaliyette bulunan firmaların ağırlığının son derece düşük olmasıdır. Bunun için, inovatif, yarışmacı rekabete sahip, katma değeri yüksek olan yüksek teknolojinin sanayide ağırlık kazanacağı yapısal dönüşümün sağlanması gerekmektedir. Bu dönüşümle, teknolojinin çarpan etkisinden yararlanılabilir. Bu değişimin hayata geçirilmesinde öncelikle ortak bir strateji çerçevesinde üniversite-sanayi-devlet iş birliği sağlanmalıdır. Bu iş birliği sonucunda, üretilen bilimsel bilgi ekonomik gelecek vadeden inovasyonlara objektif ve tarafsız biçimde yönlendirilmelidir. Türkiye'de yeni uygulanmaya konan teknoloji yoğunluklu alanlara verilen destekler, bu dönüşümü sağlama potansiyeline sahiptir. Ancak yine de kurumsal bir iş birliği ve koordinasyon eksikliği hala mevcuttur. Ayrıca, inovasyon içeriği ve türleri açısından hem firma hem de endüstri düzeyinde yapılacak gelecekteki çalışmalarla inovasyon, rekabet ve performans arasındaki ilişkilerin doğası daha iyi anlaşılabilecektir. 


\section{Kaynakça}

Aghion. P.. N. Bloom. R. Blundell, R. Griffith ve P. Howitt. 2002, Competition and Innovation: An Inverted-U Relationship", The Institute For Fiscal Studies, $\mathrm{Wp} 02 / 04$.

Anderson, T. W., ve Hsiao, C. 1981, "Estimation of Dynamic Models with Error Components", Journal of the American Statistical Association, 76(375), 598606.

Anderson, T. W., ve Hsiao, C. 1982, "Formulation and Estimation of Dynamic Models Using Panel Data", Journal of Econometrics, 18, 47-82.

Arellano M., ve Bond, S. 1991, "Some Tests of Specification for Panel: Monte Carlo Evidence and An Application to Employment Equations", Review of Economic Studies, 58, 277-297.

Arellano M., ve Bover, O. 1995, "Another Look at the Instrumental Variable Estimation of Error-Components Models", Journal of Econometrics, 68, 2951 .

Arrow, K. 1962, "Economic Welfare and the Allocation of Resources for Invention." In The Rate and Direction of Inventive Activity: Economic and Social Factors, A Report of the National Bureau of Economic Research, 609625 .

Avlonitis, GJ., ve H. Salavou. 2007, "Entrepreneurial Orientation of SMEs, Product Innovativeness, and Performance", Journal of Business Research, 60(5), 566-575.

Baltagi, B. H. 2005, Econometric Analysis of Panel Data, Third Edition, England, John Wiley\&Sons, Ltd.

Bessen, J., ve E. Maskin. 2009, "Sequential Innovation, Patents, and Imitation", The RAND Journal of Economics, 40(4), 611-35.

Blundell R., ve Bond S. 1998, "Initial Conditions and Moment Restrictions in Dynamic Panel Data Models", Journal of Econometrics, 87, 115-143.

Blundell, R. ve S. Bond. 2000, "GMM Estimation with Persistent Panel Data: An Application to Production Functions", Econometric Reviews, 19, 321-340.

Bond, S. 2002, "Dynamic Panel Data Models: A Guide to Micro Data Methods and Practice", CEMMAP Working Paper, No: Cwp0209, 1-36.

Branch, B. 1974, "Research and Development Activity and Profitability: A Distributed Log Analysis”, Journal of Political Economy, 82(5), 999-1011.

Cainelli, G., R. Evangelista ve M. Savona. 2006, "Innovation and Economic Performance in Services: A Firm-Level Analysis", Cambridge Journal of Economics, 30(3), 435-458. 
D’Angelo, A. 2012, "Innovation and Export Performance: A Study of Italian High-Tech SMEs", Journal of Management and Governance, 16, 393-423

Erickson, G. ve R. Jacobson. 1992, “Gaining Comparative Advantage Through Discretionary Experience: The Returns to R\&D and Advertising", Management Science, 38(9), 1264-1279.

Forsman, H., ve S. Temel. 2011 "Innovation and Business Performance in Small Enterprises, An Enterprise-Level Analysis", International Journal of Innovation Management, 15(3), 641-665.

Freel, MS. 2000, "Do Small Innovating Firms Outperform Non-innovators?", Small Business Economics, 14(3), 195-210.

Hansen, L.P. 2002, "Large Sample Properties of Generalized Method of Moments Estimators", Econometrica, 50, 1029-1054.

Harris, R., ve Q. C. Li. 2009, "Exporting, R\&D, and Absorptive Capacity in UK Establishments", Oxford Economic Papers, 61(1), 74-103.

Hart, O. D. 1983, "The Market Mechanism as An Incentive Scheme", Bell Journal of Economics, 14(2), 366-382.

Hartmann, G. C., M. B. Myers ve R. S. Rosenbloom. 2006, “Planning Your Firm's R\&D Investment", Research Technology Management, 49(2), 25-36.

Heunks, FJ. 1998, "Innovation, Creativity and Success", Small Business Economics, 10(3), 263-272.

Hitt, M. A., Hoskisson, R. E., Ireland, R. D., ve Harrison, J. S. 1991, "Effects of Acquisitions on R\&D Inputs and Outputs", Academy of Management Journal, 34(3), 693-706.

Holmstrom, B. 1982, "Moral Hazard in Teams", Bell Journal of Economics, 13(2), 392-415.

Hsiao, C. 2003, Analysis of Panel Data, Second Edition, United Kingdom: Cambridge University Press.

Huergo, E ve J. Jaumandreu. 2004, “Firms' Age, Processes Innovation and Productivity Growth", International Journal of Industrial Organization, 22(4), 541-559.

Jaffe, A.B. 1986, "Technological Opportunity and Spillovers of R\&D”, American Economic Review, 76(5), 984-1001.

Kamien, M. I. ve N. L. Schwartz 1975, "Market Structure and Innovation: A Survey", Journal of Economic Literature, 13(1), 1-37.

Kannebley, S Jr., JV Sekkel ve BC Araujo. 2010, "Economic Performance of Brazilian Manufacturing Firms: A Counterfactual Analysis of Innovation Impacts", Small Business Economy, 34(3), 339-353. 
Kim,W.J., ve J.D. Lee. 2009, "Measuring The Role of Technology-Push and Demand-Pull in The Dynamic Development of Semiconductor Industry: The Case of The Global DRAM Market”, Journal of Applied Economics ,7(1), 83108.

Levin, R. C., W. M. Cohen ve D. C. Mowery. 1985, "R \& D Appropriability, Opportunity, and Market Structure: New Evidence on Some Schumpeterian Hypotheses", The American Economic Review,75(2), 20-24.

Lopez Rodriguez, J., ve Garcia Rodriguez, R. M. 2005, “Technology and Export Behaviour: A Resourcebased View Approach”, International Business Review, 14(5), 539-557.

Nassimbeni, G. 2001, "Technology, Innovation Capacity, and The Export Attitude of Small Manufacturing Firms: A Logit/Tobit Model”, Research Policy, 30(2), $245-262$.

Nickell, S., D. Nicolitsas ve N. Dryden 1997, "What Makes Firms Perform Well”, European Economic Review, 41(3-5), 783-796.

McCutchen Jr, W. W. ve Swamidass, P. M. 1996, "Effect of R\&D Expenditures and Funding Strategies on the Market Value of Biotech Firms", Journal of Engineering and Technology Management, 12(4), 287-299.

Oh, C., Y. Cho ve W. Kim. 2015, “The Effect of A Firm's Strategic Innovation Decisions on Its Market Performance", Technology Analysis \& Strategic Management, 27(11), 39-53.

Özçelik, E., ve Taymar, E. 2004, "Does Innovativeness Matter for International Competitiveness in Developing Countries", Research Policy, 33(3), 409-424.

Pegels, C. C., ve Thirumurthy, M. V. 1996, "The Impact of Technology Strategy on Firm Performance", IEEE Transactions on Engineering Management, 43(4), 246-249.

Pesaran, M. H. 2004, “General Diagnostic Tests for Croos Section Dependence in Panels", Universty of Cambridge, Fakulty of Economics, Cambridge WP 0435 in Economics.

Pesaran, M. H. 2007, "A Sample Panal Unit Root Test in the Presence of Cross Section Dependence”, Journal of Applied Econometrics, 22 (2), 265-312.

Rochina-Barrachina, ME., JA. Mañez ve JA. Llopis. 2010, "Process Innovations and Firm Productivity Growth", Small Business Economics, 34(2), 147-166.

Rogers, M. 2004, "Competition, Agency and Productivity", International Journal of the Economics of Business, 11(3), 349-367.

Roodman, D. 2009, "How to Do xtabond2: An Introduction to "Difference" and "System" GMM in Stata," The Stata Journal , 9(1), 86-136. 
Souare, M. 2013, "Canada-US Productivity Gap: The Role of Competition Intensity Differential", International Review of Applied Economics, 27(3), 404-428.

Sung, N. 2014, "Market Concentration and Competition in OECD Mobile Telecommunications Markets", Applied Economics, 46(25), 3037-3048.

Tassey, G. 1983, "Competitive Strategies and Performance in Technology-Based Industries”, Journal of Economic Business, 35 (1), 21-40.

Tsao, S-M. ve G-Z, Chen. 2015, "The Impact of Internationalization on Performance and Innovation: The Moderating Effects of Ownership Concentration", Asia Pacific Journal of Management, 29, 617-642.

Verhees, F, M Meulenberg ve J Pennings. 2010, "Performance Expectations of Small Firms Considering Radical Product Innovation", Journal of Business Research, 63(7), 772-777.

Wignaraja, G, 2007, "Foreign Ownership, Technological Capabilities and Clothing Exports in Sri Lanka", Journal of Asian Economics, 19(1), 29-39.

Windmeijer F. 2005, "A Finite Sample Correction for The Variance of Linear Efficient Two-Step GMM Estimator”, Journal of Econometrics, 126(1), 25-51.

Wooldridge, J. M. 2002, Econometric Analysis of Cross Section and Panel Data, England: The MIT Press.

Yerdelen Tatoğlu, Ferda. 2017, Panel Zaman Serileri Analizi, İstanul: Beta Yayınları. 